\title{
She deserved it: Analysis of variables that influence the accountability of victims of sexual violence
}

\author{
Layanne Vieira Linhares; Ana Raquel Rosas Torres
}

Cómo citar este artículo:

Viera Linhares, L., \& Rosas Torres, A. R. (2022). She deserved it: Analysis of variables that influence the accountability of victims of sexual violence. Acta Colombiana de Psicología, 25(1), 218-229. https://www.doi.org/10.14718/ACP. 2022.25.1.14

Recibido, enero 18/2021; Concepto de evaluación, junio 4/2021; Aceptado, septiembre 27/2021

\author{
Layanne Vieira Linhares ${ }^{1}$ \\ ORCID: https://orcid.org/0000-0001-6631-9469 \\ Universidade Federal da Paraíba, João Pessoa, PB, Brasil. \\ Ana Raquel Rosas Torres \\ ORCID: https://orcid.org/0000-0002-3161-0309 \\ Universidade Federal da Paraíba, João Pessoa, PB, Brasil.
}

\begin{abstract}
This article aims to analyze the effect of the combination of the variables - victim characteristics (skin color and normativity), observer sex, Belief in a Just World, and ambivalent sexism - on sexual violence victim blaming. Three studies were conducted with university students (Study 1, $N=288$; Study 2, $N=226$; Study 3, $N=307$ ), who were asked to answer some items on victim blaming, Belief in a Just World, and Ambivalent Sexism. The ANOVA and ANCOVA analyses have shown that the combination of these variables resulted in higher black and counter-normative victim blaming. The results confirmed that victim skin color, victim normativity, and the observer sex influence victim blaming for sexual violence (study 1); that BJW predicts the attribution of the victim's accountability for sexual violence (study 2), and that only benevolent sexism, together with BJW, was responsible for predicting victim blaming for sexual violence (study 3 ).

Keywords: Victim blaming; violence against women; sexual violence.
\end{abstract}

\section{Ella se lo merecía: Análisis de variables que influyen en la rendición de cuentas de las víctimas de violencia sexual}

\begin{abstract}
La mayoría de los estudios que investigan la culpabilización de las mujeres que son víctimas de violencia sexual indican que algunas características de la víctima y del observador están estrechamente relacionadas con este fenómeno. Este artículo propone analizar el efecto de la combinación de las variables características de la víctima (color de la piel y normatividad), el sexo del observador, la Creencia en un Mundo Justo y el sexismo ambivalente, en la culpabilización de la víctima de la violencia sexual. Desarrollamos tres estudios realizados con estudiantes universitarios (Estudio 1, $N=288$; Estudio 2, $N=226$; Estudio 3, $N=307$ ), que fueron instruidos para responder algunos ítems sobre culpar a la víctima, creer en un mundo justo y sexismo ambivalente. Los análisis, ANOVA y ANCOVA, mostraron que la combinación de estas variables dio como resultado una mayor culpa atribuida a la víctima negra y la contranormativa. Los resultados confirmaron que el color de la piel de la víctima, la normatividad de la víctima y el sexo del observador influencian en la responsabilización de la víctima de violencia sexual (estudio 1), que la CMJ predice la responsabilización de la víctima de violencia sexual (estudio 2) y que solamente el sexismo benevolente, junto con la CMJ, fue responsable por prever la culpabilización de la víctima de violencia sexual (estudio 3 ).
\end{abstract}

Palabras clave: Culpabilización de la víctima, Creencia en un Mundo Justo, Violencia Sexual.

1 Correspondence address: Layanne Vieira Linhares (Federal da Paraíba, Cidade Universitária, João Pessoa, PB, Brazil 58051-900. E-mail: layannelinhares@hotmail.com 


\section{Introduction}

Thousands of women are victims of some type of violence in the world every day. According to the results of a global survey, around $7.2 \%$ of women over 15 years of age reported at least one case of sexual violence during their lifetime. A particularly perverse aspect of this type of violence is the blaming of the woman herself for the violence she has suffered (Abrahams et al., 2014). Most of the studies addressing this phenomenon indicate that the victim's level of blame can be influenced by several variables involved in the situation, such as the gender of the observer (Adams-Clark \& Chrisler, 2018; Hockett et al., 2016), the type of relationship with the perpetrator of the violence (Abrams et al., 2003; Murdoch \& Gonsalkorale, 2017), the victim's alcohol consumption (Angelone et al., 2018), the type of clothing (Landstrom et al., 2016), and the victim's skin color (Lewis et al., 2016).

In addition to these variables, studies show that some characteristics of the victim also influence the blame for sexual violence. Research on normativity regarding social expectations of gender roles has investigated the blaming of counter-normative women who are victims of sexual violence. According to Cialdini and Trost (1998), social norms help people understand the situations in which they are involved, understood as rules that define appropriate or desirable patterns of thought and action for the members of a group.

The meta-analysis carried out by Hockett et al. (2016) concluded that negative attitudes towards victims of sexual violence, such as blaming, tend to increase to the extent that the victim exhibits behavior that is considered suspicious or objectionable. In other words, this tends to happen with those who do violate traditional gender role expectations and deviate from normativity. This phenomenon may be related to the fact that people use social norms as the basis for their behavior in certain situations. Thus, the member who violates the rules established for that group is seen as a deviant member and tends to be rejected (Abrams et al., 2003; Hockett et al., 2016; Viki \& Abrams, 2002).

The meta-analysis by Suarez and Gadalla (2010) examined the relationship between rape myth acceptance measures (RMA) and behavioral, attitudinal, and demographic factors in 37 studies published in journals. In summary, the findings indicated that men showed significantly more support for RMA than women. Furthermore, RMA was also strongly associated with hostile attitudes and behavior towards women.

According to Glick and Fiske (1996), one of the ways to define traditional attitudes about gender roles is sexism. These authors defined sexism as the union of stereotypes about cognitive, affective, and behavioral assessments of the appropriate role in society, directed at individuals according to their gender. They identify sexism as a construct that can manifest itself in a hostile or benevolent way, thus demonstrating an ambivalence (Glick \& Fiske, 1996). Studies on sexism indicate that this phenomenon is rooted in patriarchal values and traditional norms that sustain gender inequality, and may be reflected in a greater accountability of the victim of sexual violence.

Another variable also used in sexual violence victim-blaming is Belief in a Just World (BJW). The BJW hypothesis was proposed by Melvin Lerner, stating that all individuals have a motivation, however unconscious, to believe that the world is a just place, essentially conveying the idea that everyone gets what they deserve and deserve what they get (Lerner \& Simmons, 1966). Lerner's initial studies showed that when the idea of a just world is threatened, for example, by an unjust event, individuals resort to mechanisms or strategies to defend it (Lerner \& Simmons, 1966). One of these strategies is to blame the victim, which is associated with secondary victimization.

Specifically, studies addressing the relationship between BJW and victim blaming of sexual violence indicate that individuals who adhere more to the idea that the world is a fair place, that is, with high adherence to BJW, tend to blame victims more (Landström et al., 2016). Thus, it is relevant to highlight that, in the context of sexual violence, this reality is aggravated when the color or the victim's skin is included, since black women accumulate two categories that constitute minority groups, thus suffering the consequences of gender discrimination and that due to skin color.

Thus, although some studies have explored the impact of victim skin color (Donovan, 2007), types of behaviors (Hockett et al., 2016), observer sex (Adams-Clark \& Chrisler, 2018), ambivalent sexism (Abrams et al., 2003), and BJW (Landström et al., 2016) in the process of blaming the victim of sexual violence, it is clear that these variables are explored in isolation, with no studies having been found that examine the effect of the interaction between them and the blaming of the woman victim of sexual violence. 
Therefore, considering that these variables are closely related to the victim-blaming process, the need to analyze the vulnerability caused by the interaction between them, that is, by the accumulation of categories of victims of sexual violence is highlighted. An example of this situation would be women who accumulate two or more categories that are part of socially devalued groups, such as black and counter-normative women. By analyzing the interaction between these variables, visibility is given to different forms of subordination that these victims are exposed to. In this way, we highlight the relevance of the set of studies developed in this article, which analyze how some believe systems and norms, widely shared in society, help to understand the processes that underlie the blaming of women victims of sexual violence.

\section{Overview of the studies}

Considering the importance of discussing the psychosocial processes that contribute to blaming the victim of sexual violence, the intention of this article is to analyze the effect of the combination of variables - victim characteristics (skin color and normativity), observer sex, BJW, and ambivalent sexism - on sexual violence victim blaming. To this end, three experimental studies with quantitative approaches were developed. Study 1 analyzed how a combination of the victim's characteristics (skin color and normativity), observer sex (male and female), and the interaction between these variables influence sexual violence victim blaming. Study 2 tested whether BJW is responsible for predicting different levels of victim blaming. Finally, Study 3 analyzed how the variables BJW and ambivalent sexism combine to explain the phenomenon of blaming the victim of sexual violence. It is noteworthy that the main objective of the set of studies presented below was to analyze not only the main effect of each of the variables presented, but also to analyze how the interactions between these variables combine to explain women's victim-blaming for the violence suffered.

\section{Study 1}

We believe that, in order to understand the phenomenon of victim blaming in sexual violence, it is essential to take into account the combination of variables such as gender, skin color, and normativity. Therefore, considering that the combinations of these variables can significantly affect the way of thinking, thus generating different experiences that are not reducible to the original identities that were placed on them, this study sought to analyze how the victim's characteristics (skin color and normativity), the gender of the observer (male and female), and the interaction between these variables influence the blaming of the victim of sexual violence.

Based on the results of Donovan's (2007) studies indicating that victim's skin color and observer gender are responsible for predicting different levels of victim blaming, as well as those studies investigating the influence of information about particular types of victim behavior on victim blaming for the violence they experienced (Hockett et al., 2016), the following hypotheses are proposed:

H1a: Black victims will be blamed more than white ones. H1b: Counter-normative victims will be blamed more than normative ones.

$\mathrm{H} 2$ : Men will blame the victims more than women will H3: Black and counter-normative victims will be blamed more.

H4: Black and counter-normative victims will be blamed more by men.

\section{Method}

\section{Study type and design}

This is a $2 \mathrm{X} 2$ experimental study, with a between-subjects design, in which participants were randomly assigned to one of four conditions (victim's skin color: white vs. black) x (victim's normativity: normative behaviors vs. counter-normative behaviors).

\section{Experimental Scenario}

To develop the scenario used, online newspapers were monitored for two months and news about sexual crimes were collected. From these new items, the described scenario is constructed.

Initially, pilot studies were carried out to refine the scenario that would be used as the guiding thread of the ideas advocated here. The story described varied with respect to the victim's skin color, manipulated through images 
(white vs. black) and the victim's normativity, manipulated through information about the victim's behavior (normative vs. counter-normative behaviors).

The smutted photos presented were limited only to the victim's face, with no information about their clothes and accessories, only their stereotypical features such as hair, nose and lips. These photos were chosen from the websites http://www.faceresearch.org/http://pics.psych.stir.ac.uk/and were tested for attractiveness in a single item on a 7-point Likert scale, by 20 college students. The two photos with equivalent levels of attractiveness were used. It is also emphasized that the story mentioning that the victim was at a party and had drunk a lot helps reinforce counter-normative behavior. The added information only helped to emphasize the counter-normative behavior presented in the situation.

The experimental scenario used was previously tested in a pilot study, with the participation of 10 university students, 5 for each experimental condition (normative $\mathrm{x}$ counter-normative behaviors). In this step, the participants were asked, after reading the story, to indicate whether they considered the woman's behavior as socially accepted by society or not and to justify their response. The results showed that all participants confirmed that the behaviors described in the experimental scenario were consistent with what society considered acceptable or not. The story presented in the normative victim condition is described below:

"Eduardo was invited to a freshman hazing event at a student fraternity, promoted by the upperclassmen from his department, and decided to go. When he gets there, he realizes that most of his classmates have already drunk too much and are quite "happy". Eduardo notices a young lady who is quite drunk and is talking to an apparently sober young man. He sees that the boy is talking into her ear and leads the way to one of the bathrooms in the house. Eduardo notices that she is a little resistant to go, but ends up giving in and accompanies the boy, walking staggeringly. He hears his classmates talking about this girl, commenting that they had never seen her drinking, as she had never attended class parties and was very discreet about dating. Minutes later, he watches as the boy walks off alone, hurrying and zipping his pants, as he hears the girl call for help".

For the counter-normative victim condition, the characteristics described about the girl were as follows: "He hears his colleagues talking about this girl, commenting that she usually attends many parties, drinks a lot, and that she has already been with almost all the boys in the class". The victim's picture was placed on the questionnaires next to the story presented to the participants. After reading the story, participants were instructed to consider the photo of the girl involved in the situation and answer some questions related to the situation described.

\section{Measurement}

An item on victim blaming the victim, adapted to Portuguese from the study by Katz et al. (2017) was used as the dependent variable: "If the girl hadn't been drinking, she probably could have avoided this situation". The participants' task was to indicate the point on the scale that was closest to their opinion, ranging from $1=$ strongly disagree to $7=$ strongly agree. The participants then answered a questionnaire with sociodemographic data, consisting of questions related to gender, age, and skin color.

\section{Procedures}

Data collection. The questionnaires were administered in the classrooms, collectively. All data were collected by the same researcher. After signing the free and informed consent form, the participants were instructed to respond to the instrument individually, being randomly assigned to one of the four experimental conditions.

Data Analysis. The analyses were carried out using SPSS (Statistical Package for the Social Sciences), version 20. A $2 \times 2 \times 2$ ANOVA was performed, taking as independent variables the color of the victim's skin (white vs. black), the victim's normativity (normative vs. counter-normative behaviors), and the observer sex (male vs. female) as independent variables. And victim guilt as the dependent variable.

\section{Results}

Initially, it was emphasized that the analyses were conducted by testing the main effect of the participants' sociodemographic variables (gender, age, and skin color), which indicated a significant effect only for gender. Thus, the analyses were performed using only this sociodemographic variable. Results showed that the main effects of victim skin color $(F(1,287)=42.28, p=.000)$ and victim normativity $(F(1,287)=26.80, p=.000)$, were significant, indicating that 
Figure 1

a) Blaming the victim according to the interaction between the victim's skin color and normativity; b) Blaming the victim according to the interaction between the victim's skin color and normativity, and the observer sex

a)

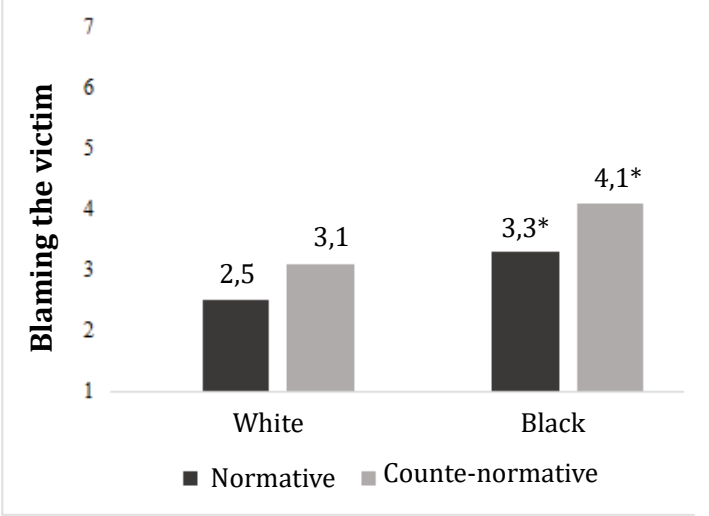

black victims $(M=3.7 ; S D=.098)$ were blamed more than white victims $(M=2.8 ; S D=.096)$ and that the counter-normative victims $(M=3.6 ; S D=.095)$ were blamed more than the normative victims $(M=2.9 ; S D=.099)$.

Likewise, the main effect of the observer sex was also significant $(F(1,287)=3.911, p=.049)$, indicating that males $(M=3.5 ; S D=.105)$ blamed more than females $(M=3.1 ; S D=.109)$. These results confirm the proposed hypotheses that black victims would be blamed more than white victims (H1a), that counter-normative victims would be blamed more than normative victims (H1b), and that men would blame more than women $(\mathrm{H} 2)$.

The results of the two-way interaction between victim skin color and normativity indicated that there was no significant effect $(F(1,287)=.094, p=.760)$. Nevertheless, when analyzing pairwise comparisons separately (Judd et al., 1995), a statistically significant difference could be ascertained when the means of the two experimental conditions were compared (Figure 1a), indicating that, in both conditions, the counter-normative victims were blamed more. It is emphasized here that the black and counter-normative victim was blamed even more, which confirms the proposed hypothesis (H3).

Finally, the triple interaction between the victim skin color and normativity, and observer sex, was not significant $(F(4,287)=1.353, p=.251)$. However, when analyzing pairwise comparisons, it was found that there were no statistically significant differences only between the means of the normative white woman status (Figure 1b). The result b)

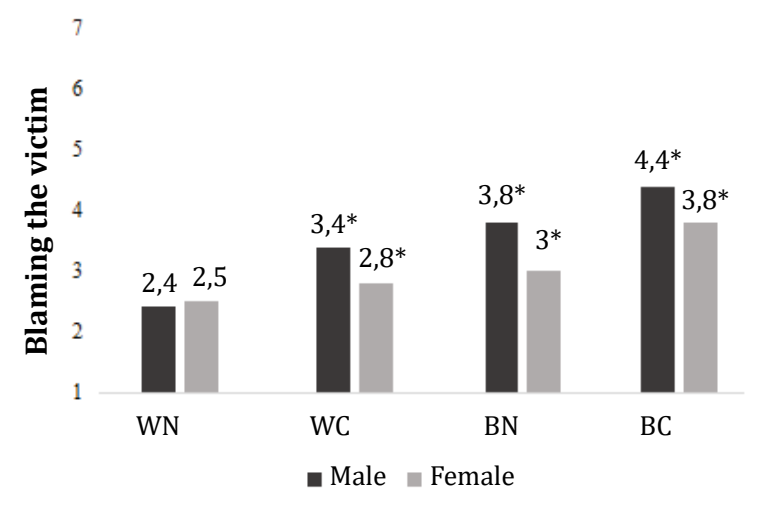

found indicated that males blamed more than females in all three experimental conditions, such that the black and counter-normative victim was blamed more by males, confirming our hypothesis 4 (H4).

\section{Study 2}

The intention of this study was to experimentally analyze whether BJW is responsible for promoting different levels of victim blaming. The following hypotheses were examined:

H4: High BJW adherence will result in higher black and counter-normative victim blaming.

H5: Men with high BJW adherence will victim blame more than women with high BJW adherence .

H6: Black and counter-normative victim blaming will be greater for men with high BJW adherence than for women with high BJW adherence .

These hypotheses were formulated considering that most studies analyzing the relationship between sexual violence victim blaming and BJW indicate that the higher the BJW, the higher the victim blaming (Landström et al., 2016; Pinciotti \& Orcutt, 2017); that some research indicates that the victim group affiliations are an important variable in explaining BJW- based victim blaming (Halabi et al., 2015; Modesto \& Pilati, 2017); that violation of traditional norms influences female sexual violence victim blaming (Hockett et al., 2016), and that men with high BJW adherence tend to victim blame more (Landström et al., 2016). 


\section{Method}

\section{Participants}

Following the recommendations of Faul et al. (2007), the number of participants is justified a priori on the basis of GPower 3.1.9 software. According to the result, a minimum sample size of 214 participants was recommended to provide an $80 \%$ chance of detecting a medium moderating effect $(f=0.25, p=.05$, and power $=.80)$. Thus, this study involved 226 university students from a public institution in the city of João Pessoa-PB, of whom 106 were men and 120 women, most of whom had declared having Brown skin color $(52.7 \%)$. The age of the participants ranged between 18 and 35 years, with a mean of 20.91 years $(S D=3.51)$.

\section{Instruments}

In this study, the same questionnaire as in Study 1 was used, with just one additional BJW measure. The measure used was the revised Belief in a Just World scale with Popular Sayings (BJWPS), validated by Linhares et al., (2021, no prelo). This scale is composed of nine items that aim to measure BJW, having as an example the items "what goes around comes around" and "an eye for an eye". The items were answered on a 5-point Likert scale ranging from 1 (strongly disagree) to 5 (strongly agree). A factor analysis was carried out, corroborating its unifactorial structure, presenting an eigenvalue of 3.34, responsible for explaining $37.17 \%$ of the total variance and a Cronbach's alpha of .78 .

\section{Procedures}

\section{Data collection and Data Analysis}

The same procedure was used for data collection as in the previous study. For data analysis, in this study it was chosen to compose the variable "victim characteristics" from the combination of the two independent variables, victim's skin color (white vs. black) and normativity (normative vs. counter-normative behaviors), obtaining a four-level categorical variable: white and normative victim (WN); white and counter-normative victim (WC); black and normative victim $(\mathrm{BN})$; black and counter-normative victim (BC), since the main objective proposed was to analyze the effect of the interaction between these variables and not the isolated effects. Next, an Analysis of Covariance - $4 \times 2$ ANCOVA was performed, taking victim characteristics (WN x WC x BN x BC) and observer sex (male vs. female) as independent variables, and victim blaming as dependent variable. BJW was used as a moderating variable in this relationship.

\section{Results}

The double interaction between victim characteristics and BJW was not significant $(F(3,216)=0.183, p=.908)$, indicating that there were no statistically significant differences between any of the experimental conditions

Figure 2

a) Blaming the victim according to the interaction between the observer sex and BJW; b) Blaming the victim according to the interaction between the victim's characteristics, the observer sex, and BJW

a)

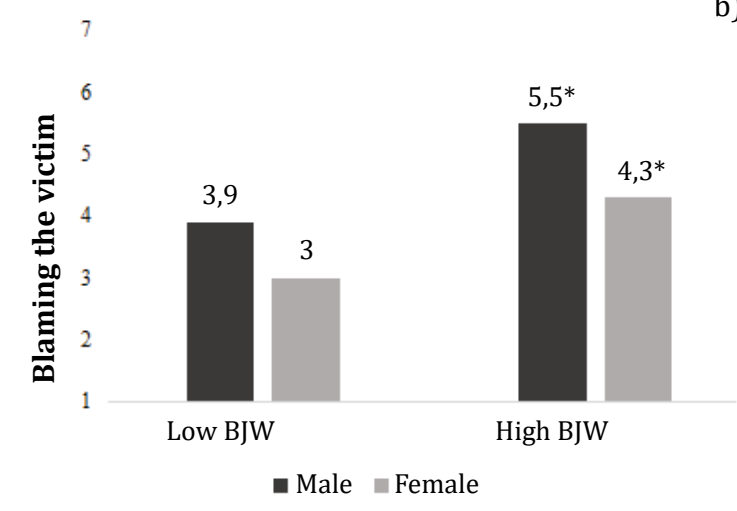

b)

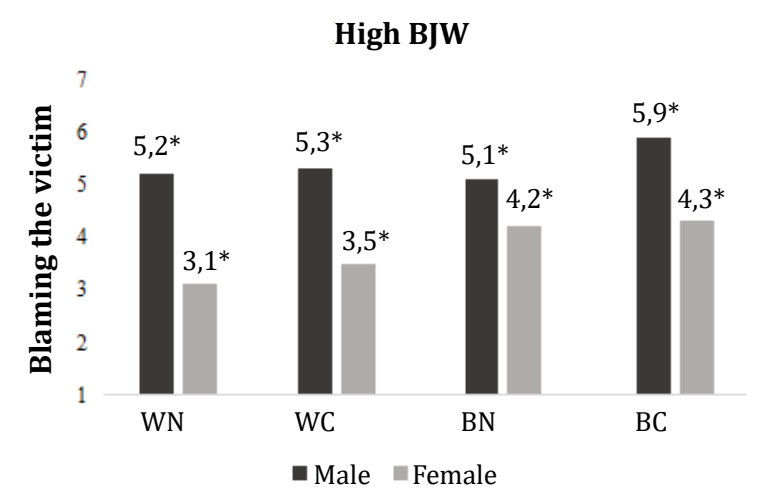


for participants with high and low BJW adherence, thus not confirming the proposed hypothesis (H4). Interaction analyses indicated a significant effect for the two-way interaction between observer sex and $\operatorname{BJW}(F(2,216)=9.951$, $p=.000)$, indicating that men with high BJW adherence blamed victims more than women with high BJW adherence (Figure 2a). With this result, hypothesis 5 was confirmed. Among participants with low BJW adherence, there was no significant difference between means.

Finally, the results of the three-way interaction between victim characteristics, observer sex, and BJW were also not significant $(F(7,216)=1.415, p=.201)$. However, pairwise comparisons showed that there were significant differences between the means of males and females with high BJW adherence in all experimental conditions (Figure 2b). There were no significant differences between the means of men with low BJW adherence. This result indicated that the men with high BJW adherence blamed the black and counter-normative victim more than women, confirming hypothesis $6(\mathrm{H} 6)$.

\section{Study 3}

Given that the studies on sexist beliefs confirm that individuals with high adherence to sexism tend to believe that women are to blame for suffering sexual violence (Abrams et al., 2003) it was postulated that the combination of these variables may influence victim blaming. Thus, this study aimed to analyze how the variables BJW and ambivalent sexism combine to explain the phenomenon of victim blaming for sexual violence. We believe that the effect of the combination of high adherence to BJW and high adherence to ambivalent sexism (hostile and benevolent) may indicate a greater tendency to blame victims more. Therefore, it was proposed that:

H7: Individuals with a high BJW adherence and high hostile sexism (H7a) and high benevolent sexism (H7b) will blame black and counter-normative victims more.

H8: Males with high BJW adherence and high hostile sexism (H8a) and high benevolent sexism (H8b) will blame victims more than females with high sexism.

\section{Method}

\section{Participants}

Following the recommendations of Faul et al. (2007), the number of participants was justified $a$ priori based on the $\mathrm{G}^{*}$ Power 3.1 .9 software. According to the result, a minimum sample size of 269 participants was recommended to provide an $80 \%$ chance of detecting a medium moderating effect $(f=0.25, p=.05$, and power $=.80)$. Thus, this study involved 307 university students from a public institution in the city of João Pessoa-PB, of whom 129 were men and 178 women, most of whom had declared having brown skin color $(51.5 \%)$. The age of the participants ranged between 17 and 37 years, with a mean of 21.09 years $(S D=3.69)$.

\section{Instruments}

The questionnaire used in this study was the same as in Study 2, plus the Glick and Fiske (1996) Ambivalent Sexism Scale adapted to Brazil by Formiga et al. (2002). This scale is composed of 22 items, divided into 11 hostile sexism and 11 benevolent sexism items. Participants were instructed to report the degree of agreement with each statement using a seven-point scale, ranging from 1 (strongly disagree) to 7 (strongly agree). A factor analysis was carried out, defining the extraction of two factors that were labeled Hostile Sexism $(\alpha=.89)$ and Benevolent Sexism $(\alpha=.82)$, both jointly explaining $43.2 \%$ of the total variance.

\section{Procedures}

\section{Data collection and Data Analysis}

Data collection followed the same procedure as the previous study. Likewise, the analysis of the results was performed following the same procedures explained in study two, adding the ambivalent sexism moderator variable. BJW was then used as the primary moderating variable and ambivalent sexism was used as the secondary moderating variable.

\section{Results}

The result of the triple interaction between victim characteristics, BJW, and hostile sexism was not significant 
$(F(3,298)=1.290, p=.278)$, indicating that there were no statistically significant differences between the means of the experimental conditions, thus not confirming the proposed hypothesis (H7a). While for the three-way interaction between victim characteristics, BJW, and benevolent sexism, a significant effect was found $(F(3,298)=4.075, p=.007)$, showing that there was a statistically significant difference between the means of participants with high BJW adherence and high benevolent sexism when compared to the normative white victim vs. counter-normative white victim conditions ( $p=.042$ ), indicating that the normative white victim was blamed more than the counter-normative white victim. And between the counter-normative white victim vs. the counter-normative black victim $(p=.003)$, indicating that the counter-normative black victim was blamed more than the counter-normative white victim (Figure 3). The result of this interaction analysis confirmed our hypothesis (H7b).

Next, the results of the triple interaction between the observer sex, BJW, and hostile sexism were not significant $(F(1,298)=.104, p=.747)$, which did not confirm the proposed hypothesis (H8a). Likewise, the three-way interaction between observer sex, BJW, and benevolent sexism was also not significant $(F(1,298)=1.280, p=.259)$. However, when analyzing pairwise comparisons of this interaction, a significant difference was observed between the means of men and women with high BJW adherence and high benevolent sexism. These results indicated that men blamed more than women (Figure 4), thus confirming our hypothesis (H8b).
Figure 3

Blaming the victim according to the interaction between the victim's characteristics, high BJW adherence, and benevolent sexism

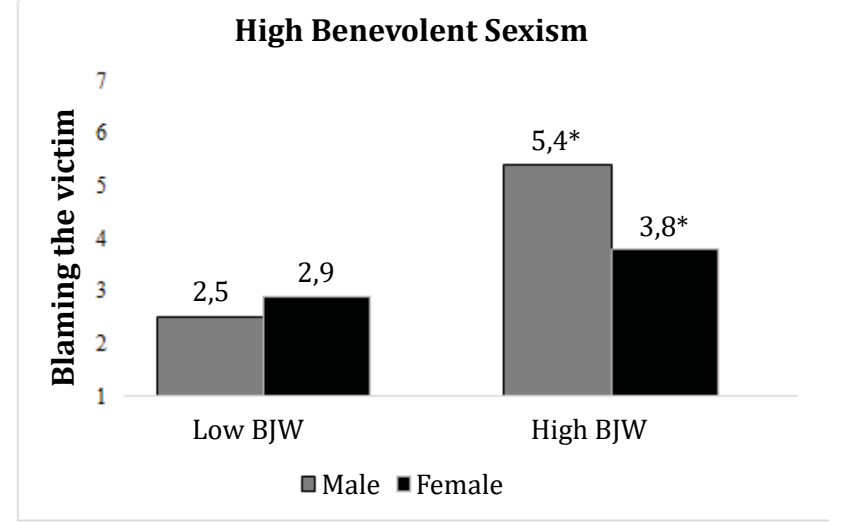

\section{General discussion}

This article analyzes the effect of combining the variables, victim's characteristics (skin color and normativity), observer sex, BJW, and ambivalent sexism on sexual violence victim blaming. The results of three experimental studies are presented as follows: Study 1 examined how victim characteristics (skin color and normativity), observer sex (male and female), and the interaction between these variables influence sexual violence victim blaming. Study 2 tested whether BJW is responsible for predicting different

Figure 4

Blaming the victim according to the interaction between the of the observer sex, high BJW adherence, and benevolent sexism

a)

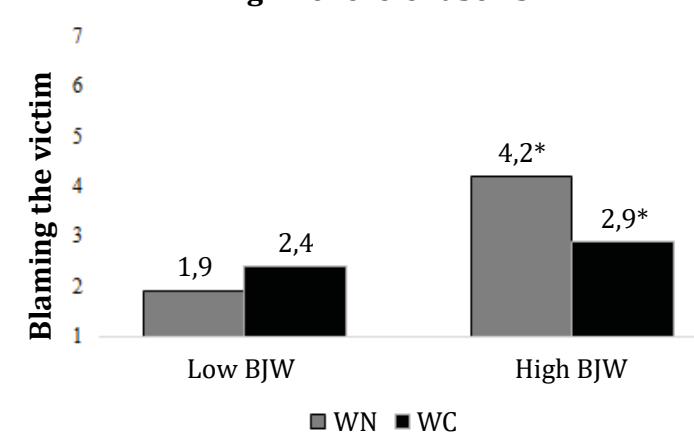

b)

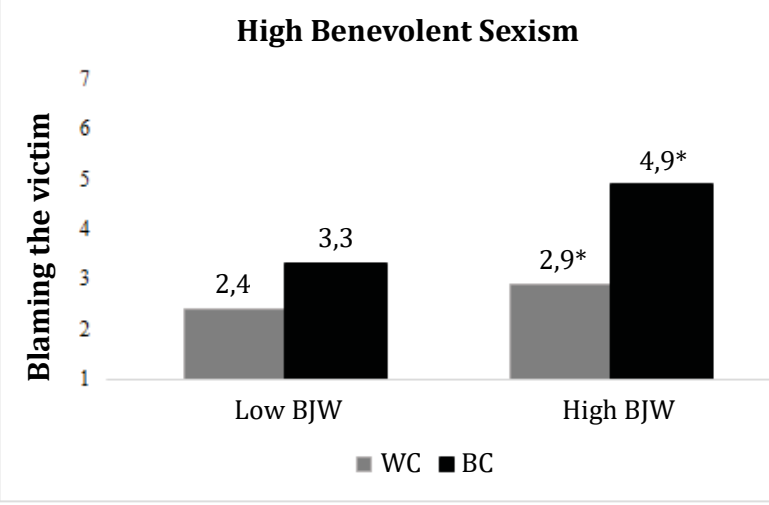


levels of victim blaming; and Study 3 analyzed how the BJW and ambivalent sexism variables combine to explain the phenomenon of sexual violence victim blaming. Taken together, the results of the three studies partially confirmed the proposed hypotheses.

Study 1 confirmed that victim skin color, victim normativity, and observer sex influence sexual violence victim blaming. As predicted, black and counter-normative victims were blamed more, and the combination of these variables resulted in greater black and counter-normative victim blaming as well. The results of the interaction between victim skin color, victim normativity, and observer sex drew attention to the fact that only in the condition in which the woman was described as white and normative was no significant difference observed between male and female victim blaming means.

This result reinforces what was found in the literature review conducted by Hockett et al. (2016) about the existence of a "real" victim, who are those belonging to a majority group and who do not violate the expectations of behaviors socially considered traditional. However, we also highlight that the same is not true for the normative black victim, thus reinforcing that the combination of the variables victim skin color and normativity affect black women even more.

Next, the results of Study 2 reinforced the finding that BJW predicts sexual violence victim blaming (Strömwall et al., 2013), confirming that BJW plays an important role in this relationship, as participants with high adherence blamed victims more, and men with high adherence blamed more than women with high adherence, corroborating what has been found in the literature (Strömwall et al., 2013). We emphasize that one of the proposed hypotheses was not confirmed (H4), as the results of the interaction between victim characteristics and BJW were not significant, indicating that, when comparing experimental conditions, participants with high BJW adherence blamed victims equally. Thus, we understand that BJW, despite having great theoretical value, did little to explain victim blaming in this scenario, leading us to believe that the predictive effect of BJW may vary depending on certain victim characteristics and the combination with other variables.

Finally, Study 3 showed that only benevolent sexism, along with BJW, is responsible for predicting victim blaming for sexual violence. Sussenbach and Bohner's (2011) study sought to analyze the acceptance of contemporary rape myths or "rape beliefs" that have been conceptualized as prejudicial beliefs (Burt, 1980) and result in intolerance towards women victims of sexual violence. In general, they act as an interpretative schema for dealing with information about sexual violence, generating biased judgments against victims and in favor of perpetrators (Eyssel \& Bohner, 2008).

Based on the results of the study proposed by Sussenbach and Bohner (2011), which indicated that benevolent sexism more strongly predicted the acceptance of rape myths, it can be considered that the results of this research corroborate the findings of the cited authors, as benevolent sexism was also a better predictor in this study.

The results of the interaction between the observer sex, BJW, and benevolent sexism indicated that men with high adherence to BJW and high benevolent sexism blamed victims more than women, confirming what has been proposed in the literature regarding sexism and BJW, that men, having different socialization processes than women, generally report more sexist beliefs and, consequently, tend to blame victims more.

Contrary to what we expected, upon comparing the experimental conditions of participants with high adherence to BJW and benevolent sexism, normative white victims were blamed more than counter-normative white victims. This result does not corroborate what has been found in studies on the relationship between benevolent sexism and victim blaming, as the literature shows that benevolent sexists tend to blame victims more when they violate traditional gender roles, that is, when they engage in counter-normative behaviors (Abrams et al., 2003). This is due to the fact that they expect women to conform to assigned traditional gender roles and that those who violate them deserve to be blamed (Glick \& Fiske, 2001).

A possible explanation for this result may originate from the fact that high BJW adherence exerts different effects against targets of different groups (Aguiar et al., 2008; Modesto \& Pilati, 2017). Studies on BJW reveal that, in some cases, a high BJW adherence results in a greater victim blaming of ingroup victims, as outgroup victims are not as threatening to maintain BJW (Lerner \& Miller, 1978). Thus, situations of injustice with these groups do not tend to threaten individuals' BJW (Aguiar et al., 2008). Thus, the fact that most of the participants declared themselves to be white may have contributed to this result. 
In addition, the fact that the experimental setting contained the information that the victim was at a party and had been drinking alcohol may have contributed to greater blame, as benevolent sexists may perceive that women who violate any expectation of female innocence contribute to their own blame (Abrams et al., 2003). On the other hand, when comparing counter-normative victims, black women were blamed more than white women. Thus, it is understood that for research on this topic, it is necessary to take into account the complexity of vulnerabilities to which women are exposed, as the accumulation of categories makes gender and skin color inequalities more potent.

\section{Final considerations}

The set of results presented shows that the variables investigated interact with each other and give rise to different experiences for the victims, which means they can be considered important variables for understanding this phenomenon.

Therefore, it is emphasized that the analysis of the intersection between variables related to the victim and the observer in cases of sexual violence victim blaming is a research that needs to be expanded, since the literature review showed that the production on this topic is still scarce. We emphasize that, although some studies have demonstrated the impact of these variables on blaming the victim of sexual violence, most studies analyze them in isolation, and no studies have been found that investigate how these variables combine and contribute to explaining this phenomenon. Therefore, we highlight the theoretical relevance of these studies in analyzing the combination of these variables, contributing to the explanation of the victim- blaming of women victims of sexual violence.

We understand that, when we investigate certain variables and how their combinations influence victim blaming, explaining what may cause some people to blame the victims and not others, we are closer to understanding this phenomenon and helping to combat it. With this, we call attention to the need to give visibility to the different forms of subordination added to the category of women, highlighting that such research can result in the development of more specific and effective public policies to address sexual violence against women, as well as provide encouragement for these women to seek help and report the violence suffered.

Despite the important results presented here, it is necessary to consider some limitations, such as the fact that the information about the victim being at a party and having drunk alcohol may somehow have influenced the responses of the participants, causing the victim to be seen as deviating from the norms established by society or reinforcing the idea that she deserved it, because she was in the wrong place and doing the wrong things. In addition, it is important to highlight that the high levels of discrimination in Brazil against minority groups addressed in the studies developed, women and blacks, may have affected the results of the studies presented.

We point out as future directions, the need to replicate these studies, to test a scenario that does not involve alcoholic beverages, and also to analyze the effect of new variables such as racism and rape myths on the relationship between skin color, victim normativity, and sex of the observer in blaming the victim for sexual violence, as well as to analyze the isolated effect of information on victim normativity.

Finally, we emphasize that these studies advance in the analysis of the combination of important variables that influence the blaming of the victim of sexual violence and contribute to maintaining a scenario of denigration and discrimination against these women. Thus, the set of studies carried out in this article reveals the predictive power of combining these variables to explain this phenomenon.

\section{References}

Abrahams, N., Devries, K., Watts, C., Pallitto, C., Petzold, M., Shamu, S., \& GarcÍa-Moreno, C. (2014). Worldwide prevalence of non-partner sexual violence: a systematic review. The Lancet, 383(9929), 1648-1654. https://doi. org/10.1016/S0140-6736(13)62243-6

Abrams, D., Viki, G. T., Masser, B., \& Bohner, G. (2003). Perceptions of stranger and acquaintance rape: The role of benevolent and hostile sexism in victim blame and rape proclivity. Journal of Personality and Social Psychology, 84(1), 111. https://doi. org/10.1037/0022-3514.84.1.111 
Adams-Clark, A. A., \& Chrisler, J. C. (2018). What constitutes rape? The effect of marital status and type of sexual act on perceptions of rape scenarios. Violence Against Women, 24(16), 1867-1886. https://doi. org/10.1177/1077801218755975

Aguiar, P., Vala, J., Correia, I., \& Pereira, C. (2008). Justice in our world and in that of others: Belief in a just world and reactions to victims. Social Justice Research, 21(1), 50-68. https://doi.org/10.1007/s11211-007-0059-3

Angelone, D. J., Mitchell, D., \& Smith, D. (2018). The influence of gender ideology, victim resistance, and spiking a drink on acquaintance rape attributions. Journal of Interpersonal Violence, 33(20), 3186-3210. https://doi. org/10.1177/0886260516635318

Burt, M. R. (1980). Cultural myths and supports for rape. Journal of Personality and Social Psychology, 38(2), 217-230. https://doi.org/10.1037/0022-3514.38.2.217

Cialdini, R. B., \& Trost, M. R. (1998). Social influence: Social norms, conformity and compliance. In D. T. Gilbert, S. T. Fiske, \& G. Lindzey (Eds.), The handbook of social psychology (p. 151-192). McGraw-Hill.

Donovan, R. A. (2007). To blame or not to blame: Influences of target race and observer sex on rape blame attribution. Journal of Interpersonal Violence, 22(6), 722-736. https://doi.org/10.1177/0886260507300754

Eyssel, F., \& Bohner, G. (2008). Modern rape myths: The Acceptance of Modern Myths About Sexual Aggression (AMMSA) Scale. In M. A. Morrison \& T. G. Morrison (Eds.), The psychology of modern prejudice (pp. 261276). Nova Science Publishers.

Faul, F., Erdfelder, E., Lang, A. G., \& Buchner, A. (2007). G* Power 3: A flexible statistical power analysis program for the social, behavioral, and biomedical sciences. Behavior Research Methods, 39(2), 175-191. https://doi.org/10.3758/BF03193146

Formiga, N. S., Gouveia, V. V., \& Santos, M. N. (2002). Inventário de Sexismo Ambivalente: sua adaptação e relação com o gênero. Psicologia em Estudo, 7(1), 103-111.doi: http://dx.doi.org/10.1590/ S1413-73722002000100013

Glick, P., \& Fiske, S. T. (1996). The Ambivalent Sexism Inventory: Differentiating hostile and benevolent sexism. Journal of Personality and Social Psychology, 70(3), 491-512. https://doi. org/10.1037/0022-3514.70.3.491

Glick, P. \& Fiske, S. T. (2001). An ambivalent alliance: Hostile and benevolent sexism as complementary justifications for gender inequality. American Psychologist, 56, $109-$ 118. https://doi.org/10.1037/0003-066X.56.2.109

Halabi, S., Statman, Y., \& Dovidio, J. F. (2015). Attributions of responsibility and punishment for ingroup and outgroup members: The role of just world beliefs. Group Processes \& Intergroup Relations, 18(1), 104-115. https://doi.org/10.1177/1368430214546067

Hockett, J. M., Smith, S. J., Klausing, C. D., \& Saucier, D. A. (2016). Rape myth consistency and gender differences in perceiving rape victims: A meta-analysis. Violence Against Women, 22(2), 139-167. https:// doi.org/10.1177/1077801215607359

Judd, C. M., McClelland, G. H., \& Culhane, S. E. (1995). Data analysis: Continuing issues in the everyday analysis of psychological data. Annual Review of Psychology, 46(1), 433-465. https://doi.org/10.1146/annurev.ps.46.020195 .002245

Katz, J., Merrilees, C., Hoxmeier, J. C., \& Motisi, M. (2017). White female bystanders' responses to a black woman at risk for incapacitated sexual assault. Psychology of Women Quarterly, 41(2), 273-285. https://doi. org $/ 10.1177 / 0361684316689367$

Landström, S., Strömwall, L. A., \& Alfredsson, H. (2016). Blame attributions in sexual crimes: Effects of belief in a just world and victim behavior. Nordic Psychology, 68(1), 2-11. https://doi.org/10.1080/19012276.2015.1026921 
Lerner, M. J., \& Miller, D. T. (1978). Just world research and the attribution process: Looking back and ahead. Psychological Bulletin, 85(5), 1030-1051. https:// doi:10.1037/0033-2909.85.5.1030.

Lerner, M.J. \& Simmons, C.H. (1966) Observer's reaction to the innocent victim: Compassion or rejection? Journal of Personality and Social Psychology, 4(2), 203-210. Available from: https://doi.org/10.1037/h0023562

Lewis, J. A., Mendenhall, R., Harwood, S. A., \& Browne Huntt, M. (2016). “Ain't I a woman?" Perceived gendered racial microaggressions experienced by Black women. The Counseling Psychologist, 44(5), 758-780. https://doi.org/10.1177/0011000016641193

Linhares, Torres \& Pereira (2021, no prelo). Revised scale of Belief in a Just World Based on Popular Sayings.

Modesto, J. G., \& Pilati, R. (2016). "Nem todas as vítimas importam": Crenças no mundo justo, relações intergrupais e responsabilização de vítimas [" Not all victims matter": belief in a just world, intergroup relations and victim blaming]. Trends in Psychology, 25(2), 763-774. http://dx.doi.org/10.9788/TP2017.2-18Pt.

Murdoch, A., \& Gonsalkorale, K. (2017). Attributions of blame in acquaintance rape scenarios: the role of blame scale presentation order. Psychiatry, Psychology and Law, 24(6), 853-865. https://doi.org/10.1080/13218719 .2017 .1315787
Pinciotti, C. M., \& Orcutt, H. K. (2017). Understanding gender differences in rape victim blaming: The power of social influence and just world beliefs. Journal of Interpersonal Violence, 36(1-2), 255-275. https://doi. org/10.1177/0886260517725736

Strömwall, L. A., Alfredsson, H., \& Landström, S. (2013). Rape victim and perpetrator blame and the Just World hypothesis: The influence of victim gender and age. Journal of Sexual Aggression, 19(2), 207-217. https://doi.org/10.1080/13552600.2012.683455

Suarez, E., \& Gadalla, T. M. (2010). Stop blaming the victim: A meta-analysis on rape myths. Journal of Interpersonal Violence, 25(11), 2010-2035. https://doi. org/10.1177/0886260509354503

Süssenbach, P., \& Bohner, G. (2011). Acceptance of sexual aggression myths in a representative sample of German residents. Aggressive Behavior, 37(4), 374-385. https:// doi.org/10.1002/ab.20390

Viki, G.T., Abrams, D. (2002). But She Was Unfaithful: Benevolent Sexism and Reactions to Rape Victims Who Violate Traditional Gender Role Expectations. Sex Roles, 47, 289-293. https://doi. org/10.1023/A:1021342912248 